\title{
8
}
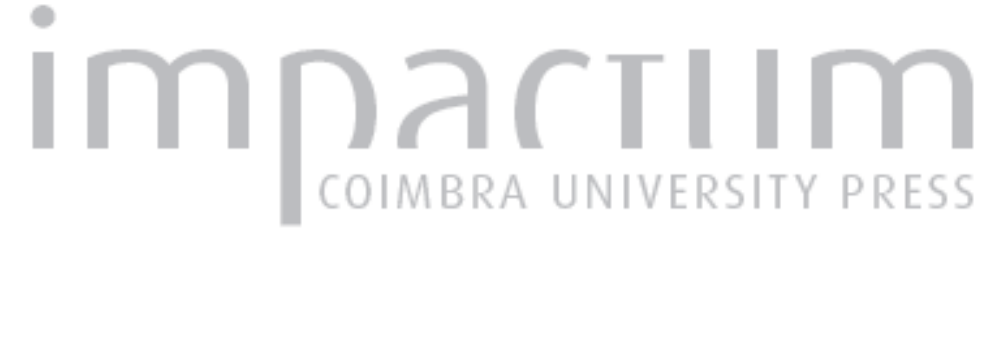

Devoção a S. João Baptista na Porta Especiosa da Sé Velha de Coimbra: (1744 a 1759)

Autor(es): $\quad$ Rodrigues, Alice Correia Godinho

Publicado por: Imprensa da Universidade de Coimbra

URL persistente:

URI:http://hdl.handle.net/10316.2/45315

DOI:

DOI:https://doi.org/10.14195/2183-8925_9-2_9

Accessed : $\quad$ 26-Apr-2023 15:34:32

A navegação consulta e descarregamento dos títulos inseridos nas Bibliotecas Digitais UC Digitalis, UC Pombalina e UC Impactum, pressupõem a aceitação plena e sem reservas dos Termos e Condições de Uso destas Bibliotecas Digitais, disponíveis em https://digitalis.uc.pt/pt-pt/termos.

Conforme exposto nos referidos Termos e Condições de Uso, o descarregamento de títulos de acesso restrito requer uma licença válida de autorização devendo o utilizador aceder ao(s) documento(s) a partir de um endereço de IP da instituição detentora da supramencionada licença.

Ao utilizador é apenas permitido o descarregamento para uso pessoal, pelo que o emprego do(s) título(s) descarregado(s) para outro fim, designadamente comercial, carece de autorização do respetivo autor ou editor da obra.

Na medida em que todas as obras da UC Digitalis se encontram protegidas pelo Código do Direito de Autor e Direitos Conexos e demais legislação aplicável, toda a cópia, parcial ou total, deste documento, nos casos em que é legalmente admitida, deverá conter ou fazer-se acompanhar por este aviso.

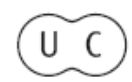


REVISTA DE HISTORIA DAS IDEIAS 9

\section{O SAGRADO E O PROFANO **}

HOMENAGEM A J. S. DA SILVA DIAS

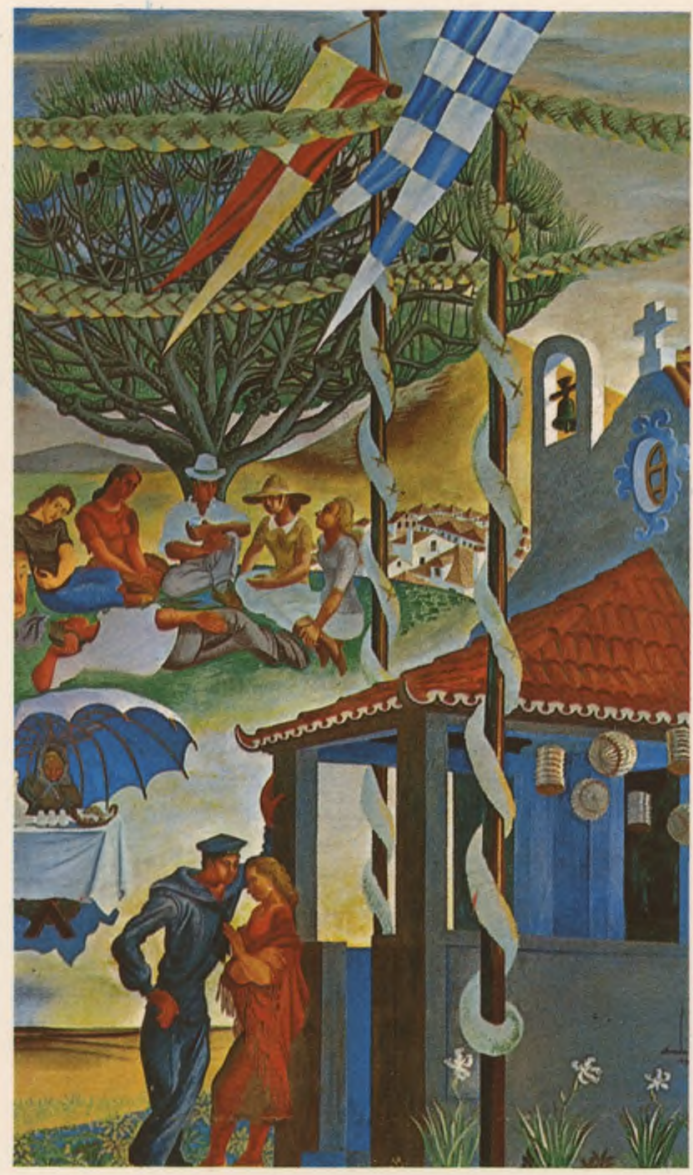

INSTITUTO DE HISTORIA E TEORIA DAS IDEIAS FACULDADE DE LETRAS 


\title{
ALICE CORREIA GODINHO RODRIGUES *
}

\author{
DEVOÇÃO A S. JOÃO BAPTISTA \\ NA PORTA ESPECIOSA DA SÉ VELHA \\ DE COIMBRA (1744 A 1759)
}

O presente trabalho integra se num plano mais amplo de investigação que pretende estudar a religiosidade popular na diocese de Coimbra durante a primeira metade do séc. XVIII, incidindo em especial sobre devoções, instituições de capelas, organizações de confrarias, festas religiosas e outras manifestações de piedade popular que para serem estudadas apelam às diversas especializações do saber histórico: história das mentalidades, verificando movimentos de sensibilidade e emotividades religiosas; história económica e social, analisando bens doados, categorias sócio-profissionais e outros aspectos que, no fundo. nos dão uma medida mais completa do «homem religioso» da época.

O conjunto das fontes históricas que constituem objecto da nossa investigação são, em especial, o fundo do Cabido e Mitra da Sé de Coimbra existente no Arquivo da Universidade de Coimbra:

Capelas (23 caixas contendo documentação avulsa);

Estatutos da See de Coimbra;

Livro das Capellas da See;

Acordos do Cabido, vols. 21 e 22; catálogo.

Documentação avulsa que está a ser organizada em

Para este artigo demorámo-nos em especial na análise do Livro $q$. serviu p. $^{a}$ se carregarem as offertas e Missas $q$. os devotos tributarem em obzéquio de S. João Baptista, cuja

* Arquivo da Universidade de Coimbra. 


\section{OSagrado e o Profano}

imagem se acha ao lado da porta traveça da Sée desta cidl e da porta de jora aonde concorrem os Fiéis Catholicos pellos m.tos prodigios q. obra Déos pella intercessão do mesmo S. ${ }^{\text {to }}$. Tratare de um livro cuja data abrange o período de 11 de Março de 1744 a 31 de Agosto de 1759, com a dimensão de 21/30 cm e constituido por 369 folhas que não são numeradas e algumas estão em branco. As capas são em pergaminho contendo uma lombada com o título: Esmollas de S. Joaõ.

\section{A porta especiosa $\left({ }^{1}\right)$}

A imagem de S. João Baptista encontra-se num dos lados da porta especiosa da Sé Velha de Coimbra, cuja construção se deve ao bispo D. Jorge de Almeida que governou o bispado de 1483 a 1543. Num desejo de bem ornamentar a sua Sé mandou construir esta porta ao gosto renascentista, sobre uma porta românica existente. «É de excelente fábrica, ornamentada com grande profusão de miudezas e lavores de notável primor e elegância». A sua construção é atribuída ao grande arquitecto João de Ruão.

Do outro lado da porta encontra-se a estátua considerada por António de Vasconcelos como representando S. Zacarias; Nogueira Gonçalves refere-se-lhe como sendo o Profeta Isaías, pois leu a abertura do cap. XVI do Livro de Isaías que diz: Emitte agnum, Domine, dominatorem terrae, numa inscrição existente numa fita larga e longa distendida nas mãos da estátua que o insigne historiador considera como significando phylacterium onde, segundo o costume, se lê uma expressão dita ou escrita pela personagem figurada. "Quando no phylacterium não se lê o próprio nome da personagem, o que é frequente, lêem-se pelo menos expressões suas, o que basta para a identificação» $\left({ }^{2}\right)$.

0) Sobre a porta especiosa da Sé Velha de Coimbra, v. Dr. António de Vasconcelos, Sé Velha de Coimbra, vols. I e II, Coimbra, 1935; Armando de Lucena, A Arte Sacra em Portugal, vol. II, pp. 110-111, Lisboa, 1943; V. Correia e A. N. Gonçalves, Inventário Artístico de Portugal, cidade de Coimbra, vol. II, Lisboa, 1947; A. Pedro Dias, A Arquitectura de Coimbra na transição do Gótico para a Renascença, 1490-1540, Coimbra, Epartur, 1982. Dissertação de doutoramento em História de Arte apresentada à Faculdade de Letras da Universidade de Coimbra.

(2) V. António de Vasconcelos, A Sé Velha de Coimbra, vol. II, Coimbra, 1935, pp. 125-126. 
De acordo com a documentação encontrada, onde ressaltam a veneração e culto que o povo concede ao precursor de Cristo, João Baptista, aparecem também algumas referências ao poder miraculoso de S. Zacarias: "Thereza Roiz da V.a de Samache p..$^{\mathrm{Q}}$ perigo em q. esteve de vida se pegou com S. Zacharias e lhe deo sua offerta, q. vay carregada no dia atrás da receita».

Em Maio de 1744 é registado no respectivo livro: «duas vellas hüa $\mathrm{p}^{\mathrm{a}}$ S. João, outra $\mathrm{p}^{\mathrm{a}}$ S. Zacharias» que renderam 480 réis; em Julho são ofertadas a $\mathrm{S}$. Zacarias duas pernas de cera que foram leiloadas por 240 réis e uma candeia de cera por 10 réis. Exemplos destes encontram-se ao longo dos registos feitos o que nos leva a concluir que a tradição popular considerava a segunda personagem, instalada no nicho esquerdo da porta especiosa, como sendo S. Zacarias, pai de S. João Baptista. Ao alto está representada a cena da Visitação (Maria, Mãe de Jesus, visita sua prima, Santa Isabel, Mãe de S. João Baptista).

A pedra de Ançã, corroída pelo tempo, pouco deixa ver da primitiva beleza desta porta; no entanto sabe-se que era constante ao longo do tempo a preocupação do Cabido em fazer o seu restauro: em 19 de Julho de 1743 o « $\mathrm{Cabb}^{\circ}$ é chamado p. ${ }^{\text {a }}$ se ponderar e rezolver a obra q. se devia fazer $p^{a}{ }^{a}$ mayor culto e adorno da Imagem de S. Joam Bapt. ${ }^{a}$ e q. estava nas Paredes fora da porta travessa desta See e q. os pios corações dos Catholicos a consagravaõ com venerações, ofertas e donativos obrigados da sua devoçaõ e também dos prodígios q. o S. ${ }^{* 0}$ obrava....» $\left({ }^{3}\right)$.

Ajustou o cónego Miguel de Sotto Mayor com o arquitecto Gaspar Ferreira a melhor forma de executar o trabalho; no entanto concluíram que não se podia fazer a obra com a grandeza exigida dado a ruína do portal $\left({ }^{4}\right)$.

Como os fiéis concorressem em grande número à Porta da Sé para implorarem alívio nos seus males, o Cabido resolveu colocar da parte de dentro da porta travessa uma caixa e uma banca com um livro e tinteiro onde se carregariam por dia todas as ofertas recebidas, encarregando-se desse serviço o P. e Manuel Pereira e Sousa, presidente dos padres capelães da Sé e na sua ausência o P.e Pedro Ferreira que teriam de recolher as ofertas, desde a abertura da Sé, até ao pôr-do-sol. Cada um dos padres poderia vender os frutos e coisas

(3) A.U.C., Acordãos do Cabido, vol. 21, fis. 106 v. e 107.

(4) Ibidem, fis. 108 v. e 109. 
usuais que se ofertassem assim como as insignias de cera: cabeças, peitos, braços, entranhas, velas, «tudo conforme os seos justos preços e os fructos e couzas uzuaes a q. ${ }^{\mathrm{m}}$ por ellas mais der, no q. se conhecerá o seu zello; e carregará neste Livro individualm. ${ }^{\text {te }}$ a qualid. $^{6}$ da offerta, e o q. ella produzio em dinh. ${ }^{\text {ro }}$...... Tratava-se de um certo pecúlio que contribuía

para o viver quotidiano do Cabido da Sé de Coimbra. No entanto este destinava grande parte das ofertas para dar o maior brilho à festa do Santo. Em 14 de Junho de 1745, reúne-se para assentar sobre a festa dedicada a S. João Baptista e delibera que teria Sermão, Missa cantada, fogo de artifício lançado de véspera, trombetas, gaitas de foles, tudo pago pelas ofertas dos devotos $\left({ }^{5}\right)$. A Igreja institucional aderia assim à vontade popular: «as ofertas ao Santo são destinadas a ser dissipadas no brilho de uma festa sem futuro» $\left({ }^{6}\right)$.

\section{O Santo. A promessa}

Segundo a teologia é Deus quem faz os milagres; para o povo cujas crenças são pouco conceptualizadas, pouco espiritualizadas e sobretudo enraizadas no concreto, é o Santo, mais acessível que o próprio Deus, quem dá o seu auxílio quando está em perigo a segurança essencial da existência individual, familiar ou social. Daí nasce a promessa que orientada para uma resposta às necessidades imediatas da existência se insere no quadro de uma economia de troca.

A S. João da porta da Sé acorriam devotos vindos das mais diversas regiões, sobretudo das zonas rurais e daí as ofertas constituírem na sua maioria produtos correntes da produção local. Aparecem-nos em maior profusão desde Março de 1744 até final do ano, ofertas de frangos, galinhas, leitões, cordeiros, milho grosso, trigo, azeite, ovos, arroz, ervilhas, coelhos, carneiros e outros géneros, ao lado de ex-votos, objectos em cera, que vendidos em leilão mensal renderam na sua totalidade 100545 réis $\left({ }^{7}\right)$. Concluímos que se trata de uma população rural ou suburbana que num gesto sacrificial acorre à porta da Sé trazendo uma oferta subtraída aos seus próprios meios de subsistência. Pouco mais tinham para dar pois nota-

(5) A.U.C., Acordaos do Cabido, vol. 22, fis. 144.

(6) G. Bataille, Théorie de la Religion, Paris, Gallimard, 1973, pp. 66,68 e 83 .

(7) A.U.C., Mapa (contendo), Lembrança dos Milagres e offertas q. se reduzem a dinheiro, anno de 1744. 
-se que as ofertas valiosas eram escassas. Em metal valioso aparecem apenas as seguintes ofertas:

\section{QUADRO I}

1 Cristo em ouro

1 Coração muito pequeno de filigrana em ouro

1 Coração em ouro.

1 Anel de ouro.

1 Coração de prata

1 Anel de prata.

1 Dedo de prata.

66 Olhos de prata.

1 Chapa de cobre bordada a ouro contendo um

Agnus Dei

\author{
1500 réis \\ $100 »$ \\ sem valor expresso \\ ॥ । !) \\ 25 réis \\ sem valor expresso \\ ") । । \\ 1320 réis
}

sem valor expresso

«O Cabido proíbe que se venda sem expressa licença qualquer oferta de ouro, prata ou seda, mortalha ou outra semelhante q. tenha especialid. ${ }^{6}$; ou possa servir p. $^{\text {a }}$ ornato do nicho do mesmo S. ${ }^{* 0}$ ou p. ${ }^{\text {a }}$ qualificar mais a See dos seos prodigios».

Os objectos em cera eram duma maneira geral representações de membros curados: cabeças, mãos, peitos, ventres, olhos, pernas e outros. Apareciam por vezes ofertas de cera a granel: "offerta de sette arr. ${ }^{\text {tes }}$ de cera a 240 cada arr. ${ }^{\text {tel }}$ e velas que ardiam em honra e louvor do Santo» ( $\left.{ }^{8}\right)$. Por vezes prometia-se simbolicamente a própria morte (ir morto) e daí o autor da promessa se envolver numa mortalha ou hábito de frade para cumprir o rito da «perambulatio».

$\mathrm{O}$ hábito correspondia também à própria morte - o frade era aquele que morria para as glórias mundanas e se envolvia num hábito à espera da morte, passagem para uma vida eterna de felicidade.

A temática da morte era uma constante na religiosidade popular desta época. Inserida na pastoral do medo que assentava sobretudo no tema do inferno, na morte em pecado mortal e no carácter terrível do juízo final, o «pagador» da

(8) O ex-voto português mais antigo que é conhecido é de 1310 e está exarado no Testamento de Lourenço Dinis. (Torre do Tombo) v. Grande Enciclopédia Brasileira, vol. X, p. 794; J. L. de Vasconcelos em O Arqueólogo Português, XXII, 1917, p. 142, datava-o de 1348. 
promessa, a quem o Santo tinha libertado de todos os perigos, pagava assim da melhor maneira a graça recebida $(*)$.

Despida a mortalha ou hábito estes eram normalmente leiloados. A mortalha rendia entre 540 réis e 1160 réis e o hábito entre 480 réis e 1200 réis. Novo índice de redução da oferta a um valor monetário frio, uniforme, que tendia a privar os gestos da sua ressonância emotiva $\left({ }^{10}\right)$.

Financiar um sermão e uma missa em honra do Santo era outra prova de agradecimento. O sermão constituía a única fonte de contacto com o mundo religioso, cultural e político. A Igreja, como aparelho ideológico, aproveitava-o para incrementar toda uma tradição de disciplina eclesiástica, no entanto não era com esta finalidade que o povo o desejava. Pagava o sermão para que fosse feita a glorificação do santo e do seu poder miraculoso de uma forma narrativa, marcado por forte carga emotiva. Era normalmente escolhido o pregador que melhor narrasse a vida do Santo especialmente os episódios miraculosos que manifestassem o seu poder. Encontrámos apenas três referências a sermões oferecidos. Seriam os sermões ditos demasiado intelectuais para as mentalidades que afluíam à Sé? Teria de ser a esmola demasiado avultada? Temos notícia de que um sermão foi mandado dizer por 10200 réis. As fontes não revelam dados suficientemente esclarecedores; movemo-nos apenas no campo das hipóteses.

Através do Quadro II verificaremos o número de missas oferecidas durante o ano de 1744 e com a respectiva esmola.

Aparecem-nos em maior profusão as missas rezadas, as mais económicas em que o oficiante diz missa em voz baixa, sem utilizar o canto e que oscilavam entre 100 a 120 réis. Nas missas cantadas, em muito menor número, o oficiante podia levantar a voz e utilizar o canto. Davam por elas de esmola 800 réis.

As missas eram afixadas numa tábua «em lugar patente p. ${ }^{\text {a }}$ q. venha a noticia de todos e se não possa allegar ignoranda», e eram oficiadas pelos padres Capelães da Sé con-

(9) V. Jean Delumeau, Le Péché et la Peur, La culpabilisation en Occident XIII - -XVIII e siècles, Paris, Fayard, 1983; Idem, La Peur en Occident, XIVe-XVIII e siècles, Dezembro, 1978; Pierre Chaunu, La mort à Paris, 16e, 17e, 18e siècles, Paris, Fayard, 1978; Michel Voyelle, Idéologie et mentalités, Paris, 1982; Piété Baroque et Déchristianisation en Provence au XVIIIe siècle, Paris, 1973; Robert Favre, La Mort au siècle des lumières, Presses Universitaires de Lyon, 1978.

(10) V., M. Jousse, L'Anthropologie du geste, Paris, Resma, 1959. 


\section{QUADRO II}

Lembrança das missas q os devotos de S. Joaõ Baptista da Porta da Sée mandaõ dizer em honra do mesmo Santo

1744

\begin{tabular}{|c|c|c|c|c|}
\hline Data & Missas & Esmolas & $\begin{array}{l}\text { Missas de S. João } \\
\text { (Tipología) }\end{array}$ & $\begin{array}{l}\text { Missas de } \\
\text { S. Zacarias }\end{array}$ \\
\hline Março & 19 & 720 réis & missas rezadas 19 & - \\
\hline Abril & 65 & $1960 »$ & missas rezadas 64 & 1 \\
\hline Maio & 89 & $4200 »$ & missas rezadas 88 & 1 \\
\hline Junho & 95 & $7720 »$ & $\begin{array}{l}4 \text { missas cantadas e } \\
91 \text { rezadas }\end{array}$ & - \\
\hline Julho & 116 & $3690 »$ & $\begin{array}{l}1 \text { missa cantada e } \\
115 \text { rezadas }\end{array}$ & \\
\hline Agosto & 143 & $10660 »$ & missas rezadas 141 & 2 \\
\hline Setembro & 63 & $3180 »$ & missas rezadas 62 & 1 \\
\hline Outubro & 56 & $3716 »$ & missas rezadas 56 & - \\
\hline Novembro & 85 & $3060 »$ & missas rezadas 85 & - \\
\hline Dezembro & 36 & $2620 »$ & missas rezadas 36 & - \\
\hline Totais & 767 & 18290 réis & $\begin{array}{c}\text { missas rezadas } 757 \\
\text { missas cantadas } 5\end{array}$ & $\begin{array}{l}\text { missas } \\
\text { rezadas } \\
5\end{array}$ \\
\hline
\end{tabular}

forme as suas antiguidades e por eles eram igualmente repartidas as esmolas.

Os milagres atribuídos a S. João Baptista eram também registados no respectivo livro. A título de exemplo apresentaremos o registo feito em 12 de Julho de 1744:

«Manoel Frz do lugar de Arcos em 22 de Janr. de 1744, andando cavando hüa pouca de area lhe cahio a barreyra em sima e ficou sepultado sem sentido algum com hüa perna quebrada, e as $\operatorname{costas}_{2} \mathrm{o}$ pescoço fóra do seo lugar e o queixo de bayxo fora taÔ bem do seo lugar, recorrendo ao $\mathrm{S}$. to varias pessoas, ficou livre e sem lezaO algum, como confessou m. ${ }^{\text {ta }}$ gente em $\mathrm{m} .{ }^{\mathrm{a}}$ prezença». 
Não se trata de uma declaração do próprio miraculado, o que normalmente acontecia, mas sim de várias pessoas que por ele intercederam perante o Santo e que o acompanharam na romagem de agradecimento — são as testemunhas do milagre e da declaração.

Aparecem-nos vários casos em que o pai surge como testemunha declarante - registo de 30 de Novembro de 1744:

«M.el Feyo da V.a de Ançaã trouxe hüa mortalha de linho pello perigo, em q. esteve sua $m$. $^{\text {er }}$ de parto, e tendo feliz saude foy o s.to Padr. ${ }^{\circ}$ de hum menino chamado JoaÕ, e sendo este de id. e de 6 mezes estando sua May com elle nos braços em hum balcam de altura de 15 palmos se arruinara 0 as pedras delle cahindo a May com a criança invocando o nome do $\mathrm{S} .{ }^{\text {to }}$ nao tiver ao perigo algum ficando a criança sobred. ${ }^{\mathrm{a}}$ entre duas pedras, que cahiraO do mesmo balcam».

Nota-se nestas declarações uma abundância de pormenores que não deixam de reflectir uma atitude perante a doença, morte e milagre. São sentimentos vivos de medo e de esperança que nos mostram estar ainda enraizada na mentalidade do século XVIII a crença da intervenção divina a ultrapassar as leis da Natureza.

Nas declarações verificadas encontrámos as doenças que apresentamos em quadro.

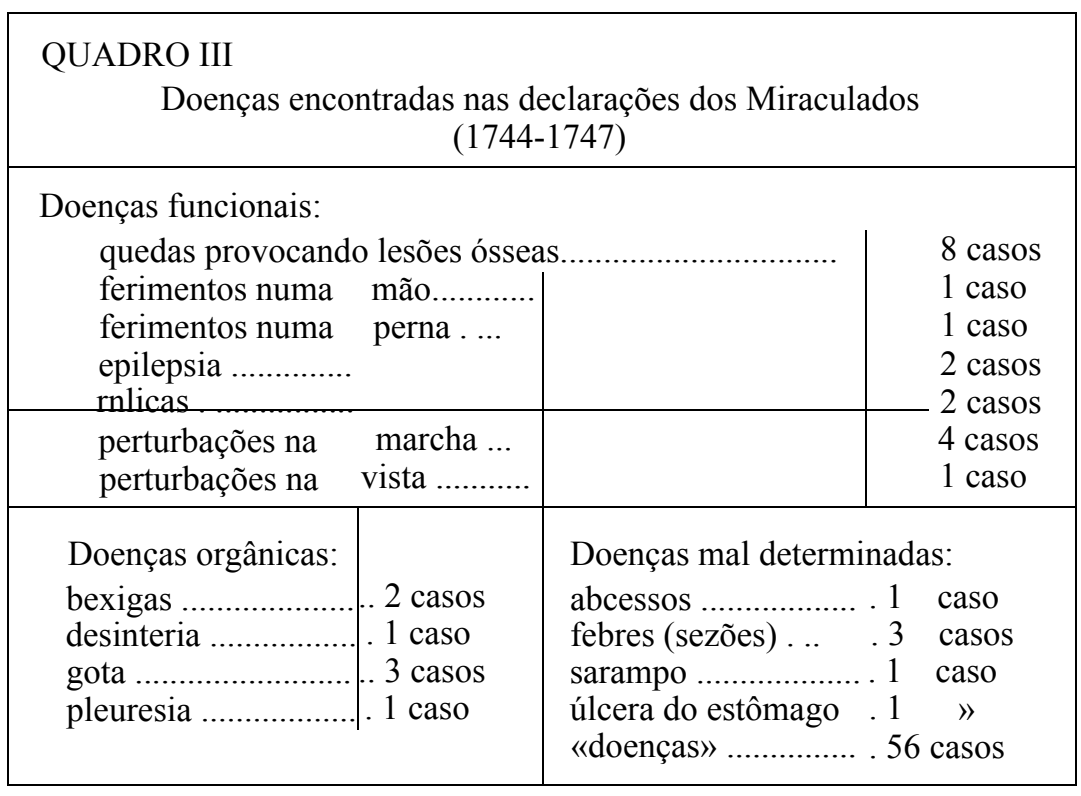


Além das doenças aparecem-nos outras causas que levam à intercessão do Santo: partos difíceis (3 casos); demandas com a Justiça (1 caso); diversos acidentes (19 casos).

Nota-se o predomínio do elemento masculino entre os miraculados e as testemunhas.

Através do quadro IV visualizar-se-á melhor esse pormenor, que se explica talvez pelo facto da mulher se deslocar com mais dificuldade do seio familiar ou porque o homem sendo o chefe de família é ele quem muitas vezes faz o voto

QUADRO IV — Repartição por sexo

\begin{tabular}{|l|c|c|c|c|}
\hline \multicolumn{1}{|c|}{ Sexo } & \multicolumn{2}{c|}{ Miraculados } & \multicolumn{2}{c|}{$\begin{array}{c}\text { T testemunhas } \\
\text { declarantes }\end{array}$} \\
\hline masculino & 45 & $40 \%$ & 66 & $63 \%$ \\
\hline feminino & 38 & $34 \%$ & 38 & $37 \%$ \\
\hline $\begin{array}{l}\text { indeterminado } \\
\text { (crianças) }\end{array}$ & 28 & $26 \%$ & & \\
\hline \multicolumn{1}{|c|}{ Totais } & 111 & $100 \%$ & 104 & $100 \%$ \\
\hline
\end{tabular}

por sua mulher e filhos e é ele quem visita o Santo em romagem de agradecimento e vem pagar a promessa:

«Manoel Fernandes Manço do Cazal do Murt.ro freg.a de Arazêde trouxe hüa mortalha de pano de linho de hüa maligna de q. esteve em perigo de vida sua molher e dous filhos».

A mulher miraculada, solteira ou viúva, é normalmente a testemunha declarante. Vem sozinha pagar a promessa mas por vezes aparece acompanhada com as testemunhas do milagre e as que fazem a declaração. Nem sempre há coincidência entre declarante e miraculado:

«P. ${ }^{\circ}$ da Costa viuvo do lugar das Torres por hü seo pastor q. esteve em perigo de vida de hum mal de bexigas deo de of ferta hum carnr. ${ }^{\circ} \gg$. 
A proporção das crianças miraculadas é relativamente elevada o que parece indicar um interesse bastante grande por parte dos pais. Não conseguimos determinar a idade e o sexo da criança, nem a origem sócio-profissional dos miraculados e testemunhas, dado que nesse ponto as declarações são muito omissas. Aparece-nos referência a um elemento do Clero: «Manoel Lopes Theyxr. ${ }^{a}$ Prior da Igr. ${ }^{a}$ de S. Bartolomeu desta cid. ${ }^{6}$ mandou 7 varas de linho de hüa grave enfermid. ${ }^{6}$ q. esteve em perigo de vida»; a um médico da Vila de Mangualde, José de Quadros Botto; a Antonia Bernarda, mulher do capitão-mor de Coimbra e a dois estudantes da Universidade:

«Vicente Pedro Vr.a natural de S. Joaõ de A Foz da cid.e do Porto estudante cursante nesta Un. de de gr.es feridas mortaes e hum dedo da maõ esquerda dependurado p. ${ }^{\text {la }}$ pelle ficou livre de perigo e o dedo outra ves unido» $\mathrm{C}^{11}$ ).

«Alexandre Manoel de Moraes estando para fazer hum acto em Medicina opprimido de gr. des $^{\text {dores e incapaz de }}$ tal funcaÕ se pegou com o Sto $^{\text {e }}$ de repente ficou livre e pagou um hum estômago» ( $\left.{ }^{12}\right)$.

As 108 declarações que analisámos reportam-se geograficamente em maior número à diocese de Coimbra, distribuindo-se os miraculados por zonas urbanas e rurais.

Diocese de Coimbra. 99 casos

Outras Dioceses. 6 casos

Espanha 2 casos

\begin{tabular}{|l|c|c|}
\hline \multicolumn{2}{|c|}{ QUADRO V — Residência urbana ou rural do miraculado } \\
\hline Residência Urbana & 36 & $35 \%$ \\
\hline Residência Rural & 67 & $65 \%$ \\
\hline Totais & 103 & $100 \%$ \\
\hline
\end{tabular}

(1:L) Era aluno da Faculdade de Cânones, A.U.C., Livro de Matrículas, vol. 58, fl. 264. vol. 58 , fl. 386 .

(12) Era natural de Portalegre, A.U.C., Livro de Matrículas, 


\section{Devoção a S. João Baptista}

Algumas declarações são omissas na origem geográfica dos miraculados ou por vezes não a identificam correctamente.

«TrouxeraÕ hüa mortalha a S. Joaõ por hum milagre que fez a hüa pessoa de sima de Braga».

«Hum homem da Br. a trouxe hüa mortalha de linho pello perigo em q. esteve devido se lhe disparar hüa espingarda no peito»

São esporádicos os casos aparecidos, vindos de outras dioceses. Anotámos Portalegre e Porto como dioceses de origem de dois miraculados que residem em Coimbra como estudantes da Universidade.

A fama milagrosa de S. João da Porta da Sé espalha-se assim por toda a diocese de Coimbra, sendo talvez os pregadores o centro difusor dessa devoção. Não há dúvida de que o milagre constitui, ao lado das festas, pregações, catequese e outras formas de culto, um outro método para sensibilizar as multidões ao dogma católico. Não sabemos por quanto tempo durou esta devoção. Através do livro analisado verificámos que as declarações dos milagres vão diminuindo de ano para ano:

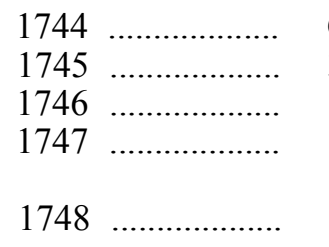

66 declarações

34

$4 \gg$

4 》 (contendo uma declaração, referências a três milagres) desaparecem a partir desta data, embora se continuem a registar apenas o número de milagres até Dezembro de 1751, o que acontece também com o registo das Missas oferecidas.

A partir de 1748 não existem declarações. Os milagres passam a ser registados numericamente; em 1748 registaram-se 327 milagres; em 1751 registaram-se 210 milagres e a partir daí não se encontram mais registos.

$\mathrm{O}$ registo das ofertas mantêm-se até Agosto de 1759: «Em 24 renderaõ as esmollas e votos 8455 réis». 


\section{QUADRO VI}

Relação dos milagres de S. João da Porta da Sé - Coimbra

Ano de 1744

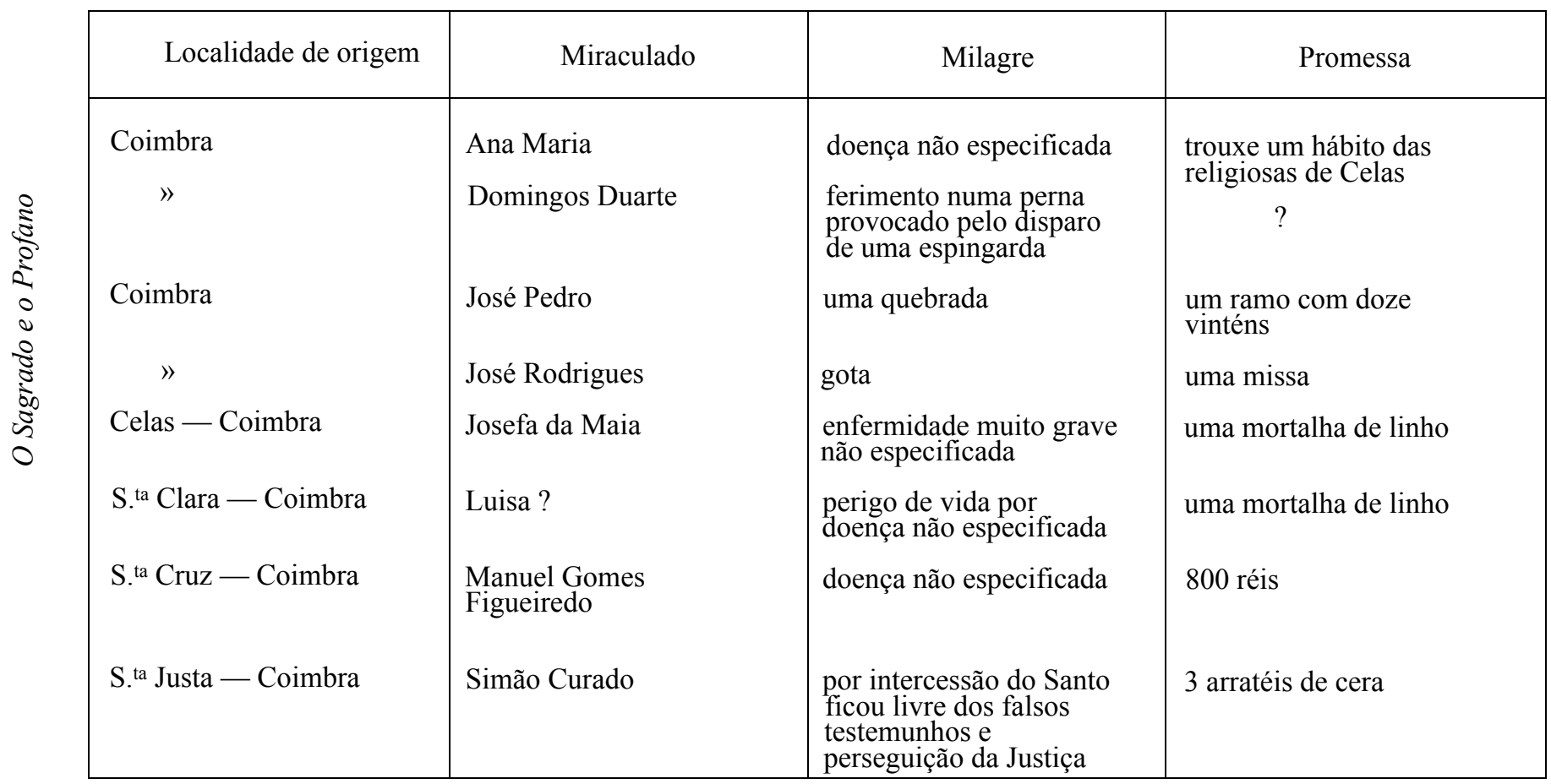




$\mid \begin{aligned} & \text { S. Bartolomeu - Coimbra } \\ & \text { S. Pedro - Coimbra } \\ & \text { Sé - Coimbra } \\ & \text { Lugar da Junqueira } \\ & \text { - termo de Coimbra } \\ & \text { Ançã } \\ & \\ & \text { Ancião } \\ & \text { Anobra (Casal } \\ & \text { de S. João) } \\ & \text { Antanhol } \\ & \text { Arazede } \\ & \text { Arcos }\end{aligned}$

Manuel Lopes Teixeira (prior da igreja de S. Bartolomeu)

\section{Maria da Costa}

Antonio Lucas

José Roiz

Manuel Feio

(testemunha)

\section{Antonio Martins}

Maria Antunes

Manuel Fernandes

Manuel Fernandes Mango

Manuel Fernandes

doença não especificada
enfermidade não
especificada
doença não especificada
gota
parto difícil de sua
mulher, passando o Santo
a ser o padrinho do
neófito. Caindo a criança
com 6 meses de um
balcão, foi salva
pelo Santo
sezões
doença não especificada
perigo de perder a vida
uma doença maligna que
o pôs em perigo de vida
caindo-lhe uma barreira
em cima, quebrou
as pernas e costelas

7 varas de linho

uma mortalha de linho

pesou uma menina

a trigo

uma missa

uma mortalha de linho

pesou o filho a trigo

uma mortalha

uma mortalha de linho

uma mortalha de pano de linho

confessou publicamente o milagre 


\begin{tabular}{|c|c|}
\hline Arzila & Maria Taborda \\
\hline Bendafé & $\begin{array}{l}\text { António Simões } \\
\text { (testemunha) }\end{array}$ \\
\hline $\begin{array}{l}\text { Carvalhais de Baixo } \\
\text { - Condeixa-a-Nova }\end{array}$ & Manuel Francisce \\
\hline Castanheira & $\begin{array}{l}\text { Ana Ferreira } \\
\text { (testemunha) }\end{array}$ \\
\hline Ceira & Amaro Francisco \\
\hline Condeixa & uma mulher \\
\hline $\begin{array}{l}\text { Espairo - S. Lourenço do } \\
\text { Bairro }\end{array}$ & Lourenço Lopes \\
\hline Espinhal — Peneia & Maria Assunção \\
\hline Ferrarias - Peneia & $\begin{array}{l}\text { António Simões } \\
\text { (testemunha) }\end{array}$ \\
\hline Figueiró dos Vinhos & João Roiz \\
\hline Foz de Arouce & António Roiz \\
\hline Furadouro & $\begin{array}{l}\text { Manuel João } \\
\text { (testemunha) }\end{array}$ \\
\hline
\end{tabular}

doença grave não especificada

uma filha em perigo de vida

enfermidade de que padecia há muito

uma grave doença sofrida por um filho

doença grave não especificada

$?$

ataques que lhe davam

grave doença não

especificada, tida

pela mulher

grave doença não

especificada

uma quebradura

uma filha com sarampo uma mortalha

pesou-a a trigo

um hábito de

S. Francisco

uma mortalha

uma mortalha de linho

mandou dizer um sermão por dez mil e duzentos

réis

pesou um filho a trigo

1 ferssura?

uma mortalha de linho

uma mortalha de pano

branco

pesou um menino a trigo

pesou a filha a trigo 


\begin{tabular}{|c|c|}
\hline Góis & $\begin{array}{l}\text { Dona Vitória } \\
\text { Isabel Botelho }\end{array}$ \\
\hline Lugar de Agrelo - Lorvão & Aurélio Cardoso \\
\hline Lousã & Helena \\
\hline Maçãs de D. Maria & Helena Curada \\
\hline Maçãs de D. Maria & $\begin{array}{l}\text { Manuel Roiz } \\
\text { (testemunha) }\end{array}$ \\
\hline Maiorca & Domitilia de Freitas \\
\hline Mangualde & $\begin{array}{l}\text { José de Quadro Botto } \\
\text { (médico) }\end{array}$ \\
\hline Melhora - Sebal & Ana Carvalha \\
\hline Mira & Pascoal Roiz \\
\hline$»$ & Isabel Francisca \\
\hline Muri e de & Gonçalo Ferreira \\
\hline$»$ & José Belo \\
\hline Outeiro da Moita & José Simões \\
\hline Outil & Luisa Francisca \\
\hline
\end{tabular}

grave doença não especificada

bexigas

obstrução no estômago durante 7 anos

doença grave não especificada

um filho em perigo de vida

doença grave não

especifiçada

doença grave não especificada

grave enfermidade

parto em perigo de vida

grave enfermidade

esteve entrevado

e curou-se

uma quebradura

grave enfermidade uma mortalha de linho

uma mortalha de linho

veio em romaria

uma mortalha

pesou o menino a trigo

uma mortalha de linho

dois anéis lisos (um de ouro e outro de prata)

uma mortalha de linho

uma mortalha de linho

uma mortalha de estopa

mortalha de pano branco,

três tranças de cabelo

2 alqueires de trigo

pesou um menino a trigo e ofereceu-o

2 alqueires de trigo 


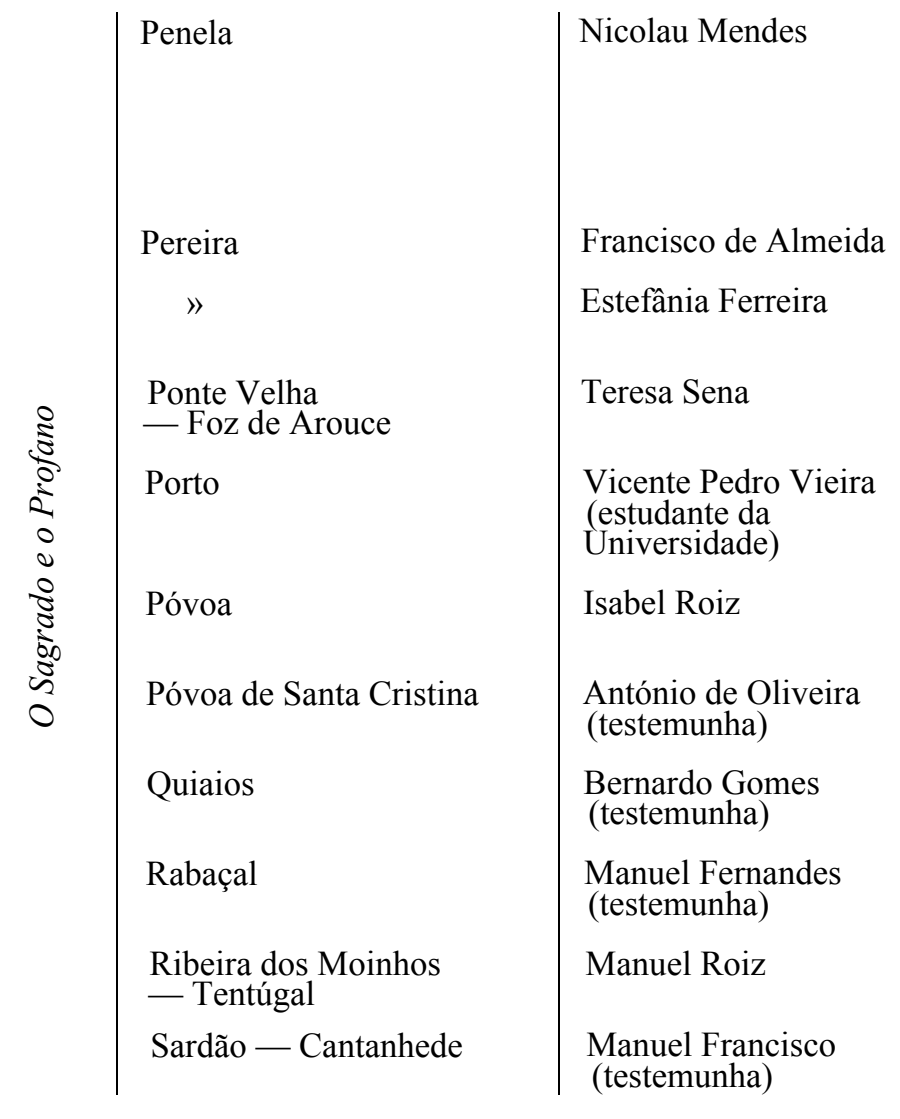

\begin{tabular}{|c|c|}
\hline $\begin{array}{l}\text { caiu-lhe um raio sobre a } \\
\text { cabeça que o lançou por } \\
\text { terra como morto e foi } \\
\text { salvo pelo Santo, assim } \\
\text { como a criança que } \\
\text { tinha nos braços }\end{array}$ & ? \\
\hline uma doença maligna & uma mortalha de linho \\
\hline $\begin{array}{l}\text { uma grave doença não } \\
\text { especificada }\end{array}$ & uma mortalha de linho \\
\hline em perigo de vida & uma mortalha de linho \\
\hline $\begin{array}{l}\text { ferida mortal na mão } \\
\text { esquerda }\end{array}$ & $?$ \\
\hline $\begin{array}{l}\text { esteve dois anos } \\
\text { entrevada }\end{array}$ & duas moletas \\
\hline $\begin{array}{l}\text { inchaço que apareceu } \\
\text { numa filha }\end{array}$ & pesou a menina a trigo \\
\hline $\begin{array}{l}\text { uma filha atacada } \\
\text { de gota }\end{array}$ & $\begin{array}{l}\text { pesou o menino a trigo } \\
\text { e ofereceu-o }\end{array}$ \\
\hline $\begin{array}{l}\text { doença grave que uma } \\
\text { filha sofria }\end{array}$ & pesou a menina a trigo \\
\hline $\begin{array}{l}\text { grave enfermidade da } \\
\text { qual esteve à morte }\end{array}$ & $\begin{array}{l}\text { uma mortalha de seis } \\
\text { varas de linho }\end{array}$ \\
\hline $\begin{array}{l}\text { queda de um filho que } \\
\text { ficou como morto }\end{array}$ & $\begin{array}{l}\text { peso do menino } \\
\text { a dinheiro }\end{array}$ \\
\hline
\end{tabular}




\begin{tabular}{|c|c|c|c|}
\hline Semide — lugar da Cegada & José Francisco & $\begin{array}{l}\text { grave doença não } \\
\text { especificada }\end{array}$ & uma mortalha de linho \\
\hline Soure & Bernarda Maria & $\begin{array}{l}\text { grave doença não } \\
\text { especificada }\end{array}$ & uma mortalha de linho \\
\hline Trouxemil & Marcos Francisco & acidente mortal & um hábito \\
\hline Vacariça & $\begin{array}{l}\text { Domingos Ferreira } \\
\text { (testemunha) }\end{array}$ & $\begin{array}{l}\text { um filho que esteve } \\
\text { três dias morco }\end{array}$ & uma toalha de estopa \\
\hline $\begin{array}{l}\text { Vendas da Pousada } \\
\text { Cernache - Coimbra }\end{array}$ & Manuel Roiz Amaro & sezões & pagou um sermão \\
\hline Verride & Nuno Duarte de S. Bento & uma doença maligna & $\begin{array}{l}\text { um hábito de } \\
\text { Santo António }\end{array}$ \\
\hline Beira & um homem & $\begin{array}{l}\text { disparou-se-lhe uma } \\
\text { espingarda no peito }\end{array}$ & uma toalha de linho \\
\hline Espanha & António do Minho & ataques contínuos & uma missa \\
\hline Espanha & Francisca Espinosa & entrevada e cega & duas moletas \\
\hline
\end{tabular}

Ano de 1747

\begin{tabular}{|c|c|c|c|}
\hline Braga & $?$ & $?$ & uma mortalha \\
\hline Carapinheira & um homem & benefícios recebidos & uma mortalha de linho \\
\hline Coimbra & Inácio da Costa & esteve em perigo de vida & um ? de 2 arratéis \\
\hline Figueiró dos Vinhos & Manuel da Silva & doença não especificada & uma mortalha \\
\hline Geria & Maria Josefa & $\begin{array}{l}\text { doença grave e sem } \\
\text { esperança de vida }\end{array}$ & $\begin{array}{l}\text { uma mortalha de pano } \\
\text { de linho }\end{array}$ \\
\hline Taveiro & uma mulher & benefícios recebidos & uma mortalha de estopa \\
\hline
\end{tabular}




\section{Conclusão}

Não queremos cair em generalizações apressadas, dado que este trabalho se insere numa pesquisa mais ampla que estamos a realizar, no entanto não podemos deixar de apresentar algumas hipóteses que poderão ser ponto de partida para uma investigação mais profunda:

1. Concluímos que os registos dos milagres são da maior importância para o estudo da história cristã sobretudo na época da Contra-Reforma. Eles trazem a crença milenária das populações em obter o socorro e protecção da divindade contra as forças hostis da natureza. A igreja católica pós-tridentina aproveita-os para sensibilizar as multidões para o dogma católico, inserindo-os na ofensiva religiosa que opôs a fé romana ao protestantismo (13).

2. Nota-se que o registo das declarações dos milagres vai diminuindo à medida que avança o século XVIII. Corresponderá a uma mudança da mentalidade popular? Será uma atitude do Cabido que evoluindo de acordo com o século se recuse em descrever certos factos que podem ser considerados como puras ilusões? Será uma reacção do «racionalismo cristão» contra o misticismo do século XVII? Tudo isto são hipóteses que poderão ter a sua resposta num estudo mais profundo e comparativo do fenómeno religioso em causa e que merece ser feito.

(13) Sobre a concepção de milagre para os reformadores, v. art. "Wunder», in Die Religion in Ge\&chicteund Gegenwart, vol. VI, cols. 1831-1847; sobre a visão católica, v. art. «Wunder» in Lexikon für Théologie, u. Kirche, vol. 10, cols. 1251-1265. 